\title{
GENETIC VARIABILITY, CHARACTER ASSOCIATION AND DIVERSITY ANALYSES FOR ECONOMIC TRAITS IN RICE (Oryza sativa L.)
}

\author{
N. Pratap ${ }^{*}$, P. K. Singh, R. Shekhar, S. K. Soni ${ }^{1}$ and A. K. Mall ${ }^{2}$ \\ Department of Genetics and Plant Breeding, Narendra Deva University of Agriculture \& Technology, \\ Kumarganj, Faizabad, U.P., 224 229, India
}

\begin{abstract}
One hundred high yielding rice genotypes were evaluated to determine character association, variability and diversity for grain yield, yield components and quality characters. High estimates of heritability, genetic advance, genotypic and phenotypic coefficients of variation were recorded for panicle hill ${ }^{-1}$, flag leaf area and grain yield hill ${ }^{-1}$. Majority of the traits showed significant and positive associations between yield and yield components like biological yield hill $^{-1}$ followed by harvest-index as most important traits which need due consideration at the time of devising selection strategy. Thus, presence of several contrasting types of inter-relationships simultaneously would bring improvement in others due to correlated responses. Path analysis might have resulted into cancellation of contrasting associations by each other which ultimately lead to lowering of the net impact. This suggested that selection would be quite efficient in improving yield and yield components in context of germplasm evaluated. The crossing between superior genotypes of above diverse cluster pairs may provide desirable transgressive segregants for developing high yielding varieties of aromatic and non-aromatic rice. Thus, hybridization of Swarna of cluster XI with promising genotypes of cluster VI (Narendra 118, Vandana, Narendra 1, Akashi and Narendra 97) is recommended.
\end{abstract}

Kew words: Correlation coefficient, diversity, genetic parameters, path analysis and rice

\footnotetext{
* Correspondence author email: npratap82@gmail.com,dr.npyadav@ymail.com

${ }^{1}$ Department of Genetics and Plant Breeding, C.S. Azad University of Agriculture \& Technology, Kanpur, U.P., India

${ }^{2}$ Central Rice Research Institute, Cuttack-753 006, India
}

Received: 07.05.2012 


\section{INTRODUCTION}

More than 90 per cent of the world's rice is grown and consumed in Asia, known as rice bowl of the world, where 60 percent of the earth's people and two thirds of world's poor live (Khush and Virk 2000). The world population is expected to reach eight billion by 2030 and rice production must increase by 50 per cent in order to meet the growing demand (Khush and Brar, 2002). Rice, being one of the important cereal crops of India, ranking first among all the cereal crops, is cultivated as pure culture mainly in wet season; cultivated in large area but characterized by poor productivity due to lack of high yielding stable varieties adaptable for different seasons and agroclimatic conditions at different parts of the country. The basic objective of this crop improvement programs is to realize a marked improvement in crop yield through various breeding methods. In order to step up the production potential, it is necessary to launch a dynamic breeding program to develop improved rice varieties suitable for different agro-climatic regions. For planning and execution of a successful breeding program, the most essential pre-requite is the availability of substantial desirable genetic variability for important characters in the germplasm collections of the plant species. The available variability in a population can be partitioned into genetic parameters such as coefficients of variation, heritability and genetic advance to serve as basis for selection of desirable genotypes than existing ones. However, yield is a complex character which is controlled by association of number of components most of which are under polygenic control. Thus the identification of important components and information about their association with yield and other traits are very useful for developing efficient breeding strategy for evolving high yielding varieties. Genetic diversity is an important tool for a crop improvement programme, as it helps in the development of superior recombinants (Manonmani and Fazlullah Khan 2003). Genetic divergence among the genotypes play an important role in selection of parents having wider variability for different traits (Nayak et al., 2004). The ultimate goal of any plant breeding programme is to develop improved genotypes which are better than the existing ones in producing the economic yield. This requires genetic amelioration through maximum utilization of allelic resources to develop ideal genotype.

\section{MATERIALS AND METHODS}

The material for the present study comprised 100 rice germplasm accessions along with four checks (Sarjoo 52, Pusa Basmati 1, CSR 30 and Narendra 97), evaluated in an Augmented Design at Research Farm of Department of Genetics and Plant Breeding, N. D. University of Agriculture \& Technology, Kumarganj, Faizabad, India, during wet season, 2009 and 2010. Twenty one days old seedlings were transplanted in $5 \mathrm{~m}^{2}$ plots with $20 \mathrm{~cm}$ x $15 \mathrm{~cm}$ spacing, using single seedling hill $^{-1}$. All the recommended cultural practices and packages were followed to raise a good and healthy crop. In each entry, ten competitive plants were selected randomly, data recorded on eleven quantitative and three qualitative traits viz, plant height $(\mathrm{PH})$, 
flag leaf area (FLA), panicle hill ${ }^{-1}(\mathrm{P} / \mathrm{H})$, panicle length (PL), spikelets panicle ${ }^{-1}(\mathrm{~S} / \mathrm{P})$, spikelet fertility (SF), 1000-grain weight (TW), biological yield $\operatorname{hill}^{-1}(\mathrm{BY} / \mathrm{H})$, grain yield hill ${ }^{-1}(\mathrm{GY} / \mathrm{H})$, harvest-index (HI), kernel length (KL), kernel breadth (KB) and $\mathrm{L}$ :B ratio (L/B), and days to $50 \%$ flowering (DF) was recorded on plot basis. The data was subjected to statistical analyses following Gomez and Gomez (1984) using Crop-Stat 7.2 (2009) statistical programme. The genetic parameters, correlation coefficients and path coefficient at genotypic and phenotypic levels were computed following Singh and Chaudhury (1985); Beale (1969) and Spark (1973) and to estimate genetic divergence and grouping of 104 genotypes into different clusters was done using Tocher's method.

\section{RESULTS AND DISCUSSION}

Analysis of variance for augmented design revealed highly significant and exploitable variability among tested genotypes for all fourteen characters and nonsignificant for the blocks. Greater variability in the initial breeding materials ensures better chances of producing desired recombinants for improvement of the crop.

\section{Genetic Parameters}

The high genotypic coefficient of variability (GCV) and phenotypic coefficient of variability (PCV) recorded for $\mathrm{P} / \mathrm{H}$ followed by FLA and $\mathrm{GY} / \mathrm{H}$ indicate the existence of wide spectrum of variability for these traits and offer greater opportunities for desired traits through phenotypic selection (Table 1). Moderate PCV and GCV values recorded for BY/H, S/P, L/B, PH, PL, HI, TW, and DF while, rest of the characters recorded low PCV and GCV. The estimates of PCV were higher than GCV for all the traits. However, Manikya and Reddy (2011) reported, small difference between GCV and PCV for all the characters under study, which indicated less influence of environment over expression of the traits. High heritability coupled with high genetic advance was observed for all the traits except SF, KL and KW. This indicates the lesser influence of environment in expression of these characters and prevalence of additive gene action in their inheritance hence, amenable of simple selection. The above mentioned three characters had high heritability with moderate genetic advance, indicating that the characters were also governed by both additive and non-additive gene actions. These results are accordance with Jayasudha and Sharma (2010).

\section{Correlation coefficient}

Out of 29 significant estimates among the total 91 correlations obtained between different character pairs, 25 correlation coefficients were positive in nature while only 4 estimates were negative (Table 2). This represents highly favourable situation for obtaining high response to selection in improving yield and yield components in rice germplasm evaluated. The measure of degree of symmetrical association between two variables or characters revealed that $\mathrm{GY} / \mathrm{H}$ had highly significant and positive correlation with $\mathrm{BY} / \mathrm{H}, \mathrm{HI}, \mathrm{TW}$ and $\mathrm{P} / \mathrm{H}$ besides having 
significant and positive association with PL. Therefore, these characters emerged as most important associates of grain yield in rice. The TW exhibited strong positive association with $\mathrm{HI}, \mathrm{BY} / \mathrm{H}, \mathrm{P} / \mathrm{H}$ and FLA besides having strong positive association with GY/H. The above characters except FLA also had strong positive association with $\mathrm{GY} / \mathrm{H}$, which augurs well for providing correlated response during selection for improving these characters. The above observations of strong positive associations between yield and yield components are in agreement with the available literature in rice (Chaudhary and Motiramani, 2003), Zahid et al., 2006 and Yadav et al., 2011. Results indicated that the taller genotypes possessed greater FLA and PL besides having late flowering, which appears logical. Janardanam et al., (2002) have also reported positive associations between these characters. Among the grain characteristics, KL had positive association with $\mathrm{PH}$ while $\mathrm{KB}$ was positively associated with DF and FLA. The negative association of L/B with KB and BY/P indicates that the genotypes with longer grains have lesser breadth as well as biomass production potential.

\section{Path coefficient analysis}

Path analysis provides clear picture of character associations for formulating efficient selection strategy. The high positive direct effects on GY/H were exerted by $\mathrm{BY} / \mathrm{H}$ and $\mathrm{HI}$ thus these characters emerged as most important direct yield components on which emphasis should be given during simultaneous selection aimed at improving grain yield of rice (Table 3). These characters have also been identified as major direct contributors towards grain yield by Mishra and Verma (2002) Jayasudha and Sharma (2010) and Yadav et al., (2011).

Biological yield hill ${ }^{-1}$ exerted considerable positive indirect effects on $\mathrm{GY} / \mathrm{H}$ via, $\mathrm{DF}, \mathrm{P} / \mathrm{H}, \mathrm{PL}, \mathrm{S} / \mathrm{P}, \mathrm{SF}, \mathrm{TW}$ and $\mathrm{KB}$ while, negative indirect effect via $\mathrm{L} / \mathrm{B}$ ratio. Harvest-index had positive indirect effect on GY/H via TW. Janardanam et al., (2002), Mahto et al., (2003), Patil and Sarawgi (2006) have also identified BY/H and $\mathrm{HI}$ as most important yield contributing traits which merit due consideration at the time of devising selection strategy aimed at developing high yielding varieties in rice.

\section{Genetic divergence}

The 104 genotype were grouped into eleven distinct clusters (Table 4). Among the eleven clusters, cluster IV was the largest with 21 genotypes, followed by cluster IX with 19 entries and cluster I with 15 entries. Clustering pattern of genotypes showed lack of any relationship between geographic origin and genetic diversity reported by Chandra et al., (2007) and Bhanumathi et al., (2010). Cluster XI exhibited very high inter cluster distances from cluster VI, II, III and I, while VI showed very high inter-cluster distance from cluster $X$ (Table 5). The crossing between superior genotypes of above diverse cluster pairs may provide desirable transgressive segregants for developing high yielding varieties of aromatic and nonaromatic rice. Considering the mean performance of genotypes, diversity of clusters

they belonged and cluster means for different characters, hybridization of Swarna of 
cluster XI with promising genotypes of cluster VI (Narendra 118, Vandana, Narendra 1, Akashi and Narendra 97), cluster II (CSR-RIL-06-165), cluster III (NDRK 50006, IR 68051-23-NDR-1-2-1-1, CSR-2K-255, Susk Samrat, Saket 4 and IR 77674-3B-82-2-14-2-AJY-3) and cluster I (Jal Priya, Taraori Basmati, Basmati 370, Kasturi and Pusa Sugandha 3 ) may be recommended for isolating transgressive segregants. Similarly, crossing of promising genotypes of cluster VI (Narendra 118, Vandana, Narendra 1, Akashi and Narendra 97) and cluster X (T 3, Kalmuhi, Kalanamak, T 100, Hazardana, Chakia 59 and Madhukar) is likely to be fruitful for obtaining desirable recombinants for developing high yielding rice varieties.

The characters identified as important direct and indirect yield contributing traits, should be given due consideration while devising selection strategy for developing high yield ideotypes. In the light of above findings it is apprehended that the improvements in characters like biological yield and harvest index will help improving the grain yield in this population. These characters also showed high heritability and genetic advance. Intercrossing of divergent genotypes with desirable traits would lead to greater opportunity for maximum amount of heterosis and utilize them for multiple crossing programmes to accumulate favorable genes in single genotypes.

\section{REFERENCES}

Banumathi, S., Manimaran, R., Sheeba, A., Manivannan, N., Ramya, B., Kumar D. and Ramasubramanian, G. V. 2010. Genetic diversity analysis of rice germplasm lines for yield attributing traits. Electronic Journal of Plant Breeding, 1 (4): 500-504.

Beale, E.M.L. 1969. Euclidean cluster analysis. A paper contributed to $37^{\text {th }}$ session of the International statistical Institute.

Chandra, B. S., Reddy T. D. and Ansari, N. A. 2007. Genetic divergence in rice (Oryza sativa L.). Research on Crops, 8 (3): 600-603.

Chaudhary, M. and Motiramani, N. K. 2003. Variability and association among yield attributes and grain quality in traditional aromatic rice accessions. Crop Improvement, 30 (1): 84-90.

Gomez K. A. and Gomez, A. A. 1984. Statistical Procedures for Agricultural Research $\left(2^{\text {nd }}\right.$ Edition). John Wiley \& Sons. Inc. (pp.680).

IRRI, 2009. CropStat 7.2 for Windows. Crop Research Informatics Laboratory, International Rice Research Institute, Los Banos, Philippines.

Janardanam, V., Nadarajan, N., and Jebaraj, S. 2002. Correlation and path analysis in rice (Oryza sativa L.). Madras Agril. J., 88 (10-12): 719-720.

Jayasudha, S. and Sharma 2010. Genetic parameters of variability, correlation and pathcoefficient for grain yield and physiological traits in rice (Oryza sativa L.) under shallow lowland situation. Electronic Journal of Plant Breeding, 1 (5): 1332-1338.

Khush, G. S. \& Brar, D. S. 2002. Biotechnology for rice breeding: progress and impact. In: Sustainable rice production for food security. Proceedings of the $20^{\text {th }}$ Session of the International Rice Commission. Bangkok, Thailand, July, 23-26. 
Khush, G. S. and Virk, P. S. 2000. Rice breeding achievements and future strategies. Crop Improvement, 27 (2): 115-144.

Mahto, R. N., Yadava, M. S., and Mohan, K. S. 2003. Genetic variation, character association and path analysis in rainfed upland rice. Indian J. Dryland Agric. Res. and Devel., 18 (2): 196-198.

Manikya, C. M. and Reddy T. D. 2011. Studies on genetic divergence in medium duration elite rice genotypes (Orzya sativa L.). The Journal of Research ANGRAU, 39 (4): 122.

Manonmani, S. and Fazlullah Khan, A. K. 2003. Analysis of genetic diversity for selection of parents in rice. Oryza, 40: 54-56.

Mishra, L. K. and Verma, R. K. 2002. Correlation and path analysis for morphological and quality traits in rice (Oryza sativa L.). Plant Archives, 2 (2): 275-284.

Nayak, A. R., Chaudhury, D. and Reddy, J. N. 2004. Genetic divergence in scented rice. Oryza, 41: 79-82

Patil, P. V. and Sarawgi, A. K. 2006. Studies on genetic variability, correlation and path analysis in traditional aromatic rice accessions. Annals of Plant Physiology 19 (1): 9295.

Singh, R. K. and Chaudhury, B. D. 1985. Biometrical Methods in Quantitative Genetic Analysis. Kalyani Publishers, New Delhi, India (pp. 229-252).

Spark, D. N. 1973. Euclidean cluster analysis. Algorithm. As. 58. Appl. Stats., 22: 126-130.

Yadav, S.K., Pandey, P., Kumar B. and Suresh, B.G.2011. Genetic architecture, interrelationship and selection criteria for yield improvement in rice (Oryza sativa L.). Pak. J. Biol. Sci. 14: 540-545.

Zahid, M. A., Akhter, M., Sabar, M., Zaheen, M., and Awan, T. 2006. Correlation and path analysis studies of yield and economic traits in Basmati rice (Oryza sativa L.), Asian Journal of Plant Sciences, 5 (4): 643-645. 
Table 1: Grand mean, estimates of phenotypic (PCV) and genotypic (GCV) coefficient of variation, heritability $\left(h^{2} b\right)$ and genetic advance in per cent of mean for 14 characters in rice

\begin{tabular}{|c|c|c|c|c|c|}
\hline \multirow[t]{2}{*}{ Characters } & \multirow[t]{2}{*}{ Grand Mean } & \multicolumn{2}{|c|}{ Coefficient of variation } & \multirow{2}{*}{$\begin{array}{l}\text { Heritability } \\
\text { in broad } \\
\text { sense }(\%)\end{array}$} & \multirow{2}{*}{$\begin{array}{c}\text { Genetic advance } \\
\text { in per cent of } \\
\text { mean }\end{array}$} \\
\hline & & PCV & GCV & & \\
\hline DF & $95.94 \pm 2.79$ & 10.72 & 10.68 & 99.30 & 21.93 \\
\hline PH & $108.68 \pm 2.98$ & 12.22 & 12.19 & 99.50 & 25.05 \\
\hline FLA & $27.27 \pm 2.29$ & 27.93 & 27.81 & 99.10 & 57.04 \\
\hline $\mathbf{P} / \mathbf{H}$ & $10.49 \pm 2.29$ & 30.89 & 30.62 & 98.20 & 62.50 \\
\hline PL & $26.96 \pm 1.97$ & 11.99 & 11.78 & 96.50 & 23.83 \\
\hline $\mathbf{S} / \mathbf{P}$ & $136.56 \pm 17.38$ & 15.63 & 15.13 & 93.70 & 30.17 \\
\hline SF & $84.94 \pm 5.24$ & 5.89 & 5.58 & 89.60 & 10.88 \\
\hline TW & $23.43 \pm 2.05$ & 10.80 & 10.46 & 93.70 & 20.86 \\
\hline BY/H & $46.37 \pm 2.97$ & 16.56 & 16.44 & 98.60 & 33.62 \\
\hline $\mathbf{G Y} / \mathbf{H}$ & $19.04 \pm 1.99$ & 20.38 & 20.13 & 97.50 & 40.94 \\
\hline HI & $41.18 \pm 5.33$ & 11.21 & 10.48 & 87.30 & 20.18 \\
\hline KL & $6.11 \pm 0.43$ & 9.17 & 8.92 & 94.40 & 17.86 \\
\hline $\mathbf{K B}$ & $2.30 \pm 0.10$ & 8.96 & 8.85 & 97.60 & 18.01 \\
\hline L/B & $2.69 \pm 0.26$ & 13.04 & 12.68 & 94.60 & 25.41 \\
\hline
\end{tabular}


Table 2: Estimates of simple correlation coefficients between 14 characters in rice

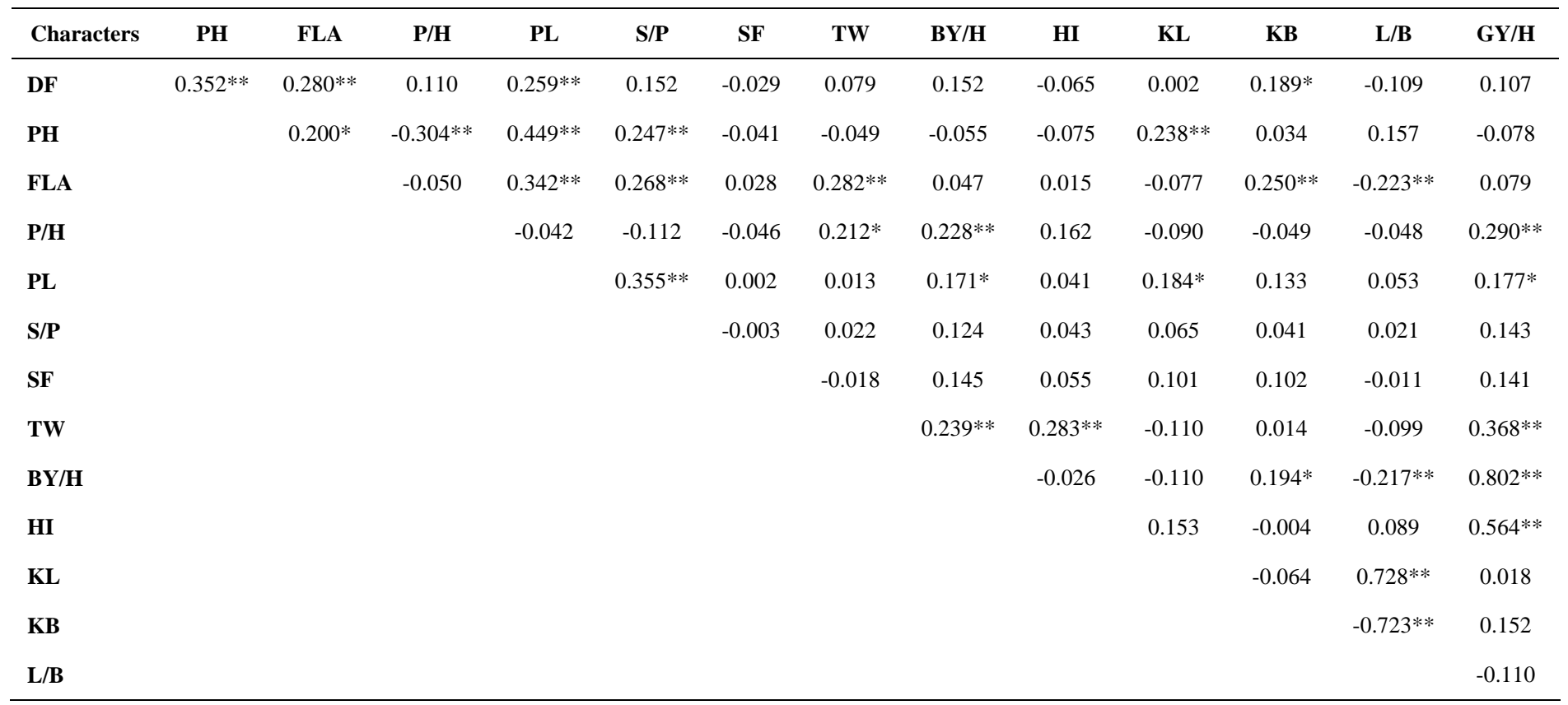

**, * Significant at 1 and 5 per cent probability levels, respectively. 
Table 3: Direct and indirect effects of 13 characters on grain yields per hill in rice

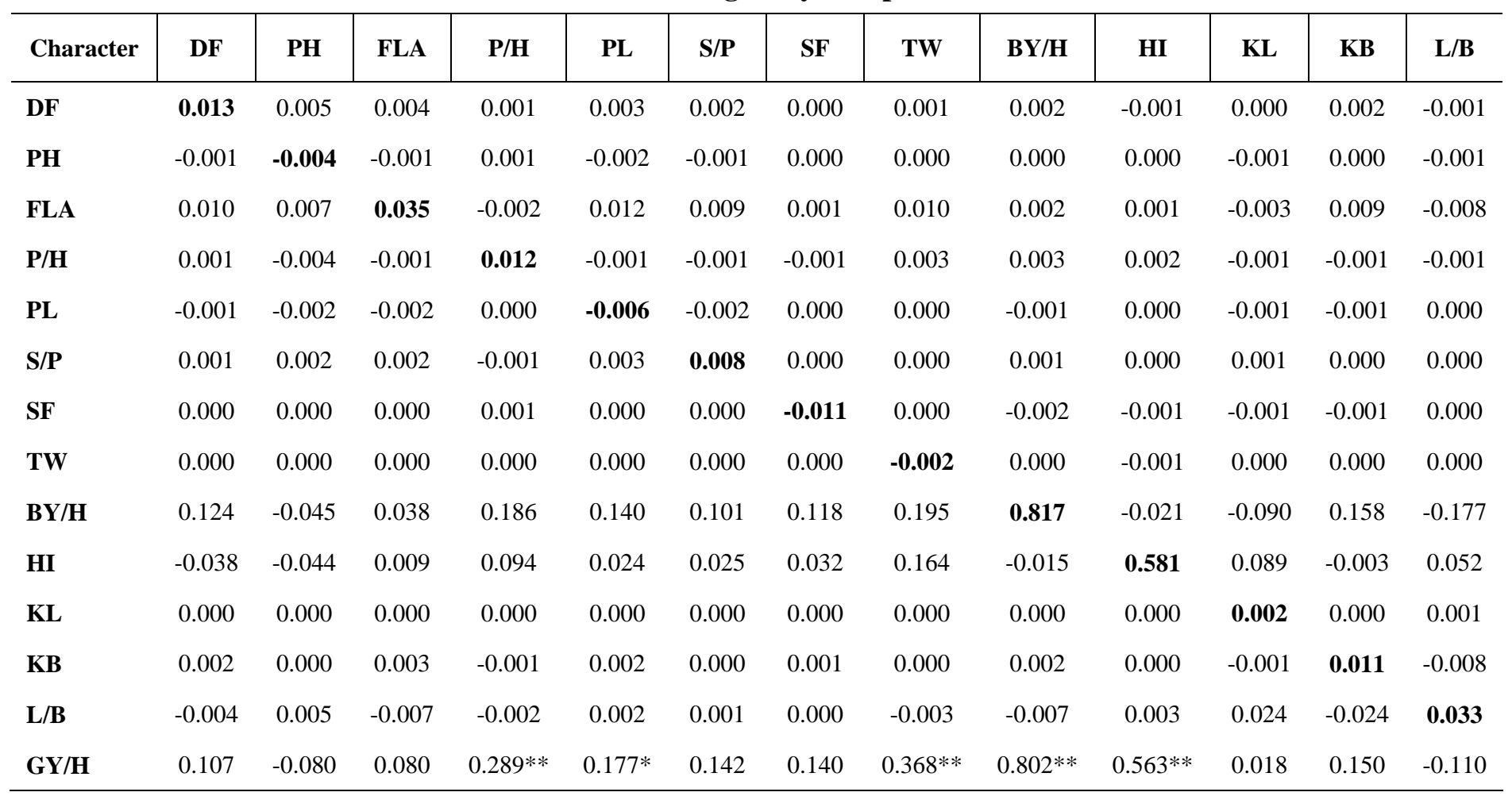

RESIDUAL EFFECT $=\mathbf{0 . 1 1 5 1}$, Bold Figure represent Direct effect 

Table 4: Clustering pattern of 104 rice genotypes based on Non-hierarchical
Euclidean cluster analysis for 14 characters.

\begin{tabular}{|c|c|c|}
\hline $\begin{array}{l}\text { Cluster } \\
\text { number }\end{array}$ & $\begin{array}{l}\text { No. of } \\
\text { genotypes }\end{array}$ & Name of genotypes \\
\hline $\mathbf{I}$ & 15 & $\begin{array}{l}\text { NDRK 50018, Jal Priya, NDRK 5014, Sonalika, Basmati 370, Pusa Basmati } \\
\text { 1, Kasturi, Pakistani Basmati, Pusa Sugandha 4, JKRH 2000(Hybrid), CSR } \\
\text { 27, Indrasan, Pusa Sugandha 3, NDRK } 50019 \text { and Taraori Basmati. }\end{array}$ \\
\hline II & 2 & CSR-RIL-06 -165 and Chaini. \\
\hline III & 10 & $\begin{array}{l}\text { NDRK 50006, NDCP 608, IR 68051-23-NDR-1-2-1-1, CSR-2K-255, NDRK } \\
\text { 50011, CSR 36, Susk Samrat, Narendra 80, Saket } 4 \text { and IR 77674-3B-8-2-2- } \\
\text { 14-2-AJY-3. }\end{array}$ \\
\hline IV & 21 & $\begin{array}{l}\text { Panvel 1, Pant Dhan 12, NDRK 5097, CSR 11, NDRK 50008, NDR } 2026 \\
\text { (Richa), AURC 02-05-1, NDR 2022, NDR 2064, CR 2472-4-28-2, Y } \\
\text { 134,Annada, TKM 9, IR 64, CSR -2K-242, IR 75395-2B-B-19-2-1-2, } \\
\text { NDRK 5087, Pant Dhan 10, NDRK 5033, NDRK } 50015 \text { and Ratna. }\end{array}$ \\
\hline $\mathbf{V}$ & 5 & FL 478, IR 59418-7B-21-3, NVSR 6029, NVSR 6030 and CSR 10. \\
\hline VI & 7 & $\begin{array}{l}\text { Narendra 118, CSR 30, Nagina 22, Vandana, Narendra 1, Akashi and } \\
\text { Narendra } 97 .\end{array}$ \\
\hline VII & 8 & $\begin{array}{l}\text { CR 661-236-1-3, CSR 13, Pankaj, Sambha Masuri, Narendra Lalmati, CR } \\
\text { 2472-1-6-2-1, Jal Lahari and NDR } 423 .\end{array}$ \\
\hline VIII & 8 & $\begin{array}{l}\text { NDRK 50012, PNR 381, NDR 2031, Pant Dhan 4, TR 2005-041, NDR } \\
\text { 8030, IR } 24 \text { and NDRK 50013. }\end{array}$ \\
\hline $\mathbf{I X}$ & 19 & $\begin{array}{l}\text { Pant Dhan 102, NDRK 5088, Raghuvansi 4, NDRRK 5026, IR 72593-B-13- } \\
\text { 3-3-1, Lalpari No. 3, Sarjoo52, NDR 3026, Sundri, Narendra 359, Jaya, } \\
\text { NDRK 50005, NDRK 50007, Narendra Usar 2, NDRK 50016, MRI 18, } \\
\text { CSR-RIL-06 -94, NDRK } 50002 \text { and Narendra Usar } 3 \text {. }\end{array}$ \\
\hline $\mathbf{X}$ & 8 & $\begin{array}{l}\text { T-3, Kalmuhi, Kalanamak, T-100, Hazardana, Chakia 59, Madhukar and T- } \\
1 .\end{array}$ \\
\hline $\mathbf{X I}$ & 1 & Swarna. \\
\hline
\end{tabular}


Table 5: Estimates of average intra (diagonal and bold) and inter cluster distances for 11 clusters in rice.

\begin{tabular}{|c|c|c|c|c|c|c|c|c|c|c|c|}
\hline Cluster & I & II & III & IV & V & VI & VII & VIII & IX & X & XI \\
\hline I & $\mathbf{0 . 4 3}$ & 1.71 & 1.54 & 2.45 & 5.51 & 8.30 & 2.67 & 1.15 & 1.63 & 2.75 & 15.16 \\
\hline II & & $\mathbf{0 . 4 2}$ & 1.73 & 4.74 & 10.39 & 6.78 & 7.56 & 4.62 & 5.09 & 6.95 & 25.58 \\
\hline III & & & $\mathbf{0 . 2 9}$ & 1.26 & 4.70 & 3.32 & 5.10 & 2.88 & 2.22 & 6.80 & 19.58 \\
\hline IV & & & & $\mathbf{0 . 3 8}$ & 1.59 & 4.43 & 3.25 & 2.04 & 0.96 & 6.21 & 13.47 \\
\hline V & & & & & $\mathbf{0 . 2 4}$ & 8.44 & 2.95 & 2.10 & 1.54 & 7.10 & 7.92 \\
\hline VI & & & & & & $\mathbf{0 . 8 7}$ & 13.81 & 10.52 & 8.12 & 17.10 & 31.33 \\
\hline VII & & & & & & & $\mathbf{0 . 3 8}$ & 0.63 & 1.04 & 1.42 & 5.73 \\
\hline VIII & & & & & & & & $\mathbf{0 . 2 0}$ & 0.51 & 1.52 & 8.77 \\
\hline IX & & & & & & & & & $\mathbf{0 . 1 9}$ & 3.01 & 9.09 \\
\hline X & & & & & & & & & & $\mathbf{0 . 5 8}$ & 8.43 \\
\hline XI & & & & & & & & & & & $\mathbf{0 . 0 0}$ \\
\hline
\end{tabular}


Table 6: Clusters means for 14 characters in rice

\begin{tabular}{lllllllllllll|l|l|l|l|l|l}
\hline Clusters & DF & PH & FLA & P/H & PL & S/P & SF & TW & BY/H & GY/H & HI & KL & KB & L/B \\
\hline Cluster I & 97.13 & 126.18 & 27.37 & 8.89 & 29.66 & 138.19 & 85.04 & 21.96 & 44.39 & 17.17 & 38.96 & 6.41 & 2.20 & 2.96 \\
Cluster II & 86.97 & 138.30 & 23.89 & 8.84 & 27.81 & 156.95 & 82.46 & 24.93 & 42.05 & 20.33 & 47.61 & 6.26 & 2.18 & 2.87 \\
Cluster III & 84.68 & 112.90 & 25.07 & 11.13 & 27.11 & 134.60 & 85.06 & 22.69 & 43.01 & 17.60 & 41.71 & 6.35 & 2.34 & 2.73 \\
Cluster IV & 89.10 & 96.76 & 25.50 & 10.00 & 25.77 & 131.45 & 85.39 & 23.51 & 46.71 & 19.24 & 41.62 & 6.09 & 2.23 & 2.75 \\
Cluster V & 95.73 & 79.43 & 25.18 & 15.51 & 22.67 & 120.15 & 84.84 & 21.96 & 44.32 & 18.33 & 41.49 & 6.00 & 2.29 & 2.63 \\
Cluster VI & 65.67 & 92.53 & 22.54 & 7.38 & 23.22 & 118.43 & 88.59 & 22.13 & 41.54 & 17.53 & 41.71 & 5.58 & 2.28 & 2.47 \\
Cluster VII & 109.53 & 109.34 & 32.64 & 9.39 & 26.71 & 145.31 & 83.92 & 23.42 & 49.25 & 20.01 & 40.89 & 5.79 & 2.41 & 2.44 \\
Cluster VIII & 103.79 & 114.17 & 25.68 & 12.42 & 27.16 & 143.34 & 82.18 & 24.90 & 44.08 & 18.70 & 42.46 & 6.13 & 2.21 & 2.78 \\
Cluster IX & 98.94 & 103.83 & 27.02 & 12.04 & 27.62 & 137.56 & 84.21 & 24.50 & 51.14 & 21.32 & 41.44 & 6.16 & 2.33 & 2.67 \\
Cluster X & 115.11 & 129.82 & 35.98 & 6.73 & 29.11 & 143.07 & 87.13 & 23.10 & 44.88 & 17.77 & 39.85 & 6.07 & 2.45 & 2.52 \\
Cluster XI & 128.70 & 83.11 & 25.75 & 26.06 & 24.06 & 105.35 & 91.23 & 24.06 & 57.86 & 27.81 & 48.07 & 5.46 & 2.49 & 2.19 \\
\hline
\end{tabular}

